\title{
Celastrol-mediated autophagy regulation in cancer
}

\author{
Muhammad Haroon and Sun Chul Kang *(1)
}

\begin{abstract}
In the last few decades, studies on autophagy regulation and its potential role in cancer therapeutics have expanded to include detailed mechanisms. Since apoptosis exhibits drug resistance in some cancers, efforts have focused on searching for compounds with autophagy modulating properties. Numerous natural compounds have been used in cancer treatment and are considered a significant research area due to their remarkable anti-cancer properties. Celastrol, a quinone methide triterpene, derived from Tripterygium wilfordii, has recently drawn much attention because of its anticancer potential. It enhances tumor suppression and induces autophagy in cancer cells by regulating signaling pathways such as Beclin-1, Akt/mTOR, ROS, NF-KB, MAPK, HSP90, and the proteasome. In the current study, we address the anticancer potential of celastrol, its effect on various cellular pathways, and describe how it functions as an autophagy modulator in cancer therapeutics and helps diminish multidrug resistance in cancer cells.
\end{abstract}

Keywords: Celastrol, Cancer, Autophagy, Mechanistic pathways

\section{Introduction}

Cancer is considered the second leading cause of global mortality, with 9.6 million deaths in 2018. This is a combinational disease wherein uncontrolled cell growth occurs and can metastasize to other parts of the body. The mechanisms involved in suppressing tumors in a normal body can differentiate between normal cells and abnormally developing cells. However, the problem arises when genes responsible for tumor suppression get altered by certain environmental factors (including radiation, pollution, and infectious agents) or routine habits of humans (such as alcohol, poor diet, tobacco consumption etc.) [1-7]. Among the several cancer types, lung cancer and breast cancer account for approximately $11.6 \%$ of the total cases prevalent globally, followed by prostate cancer (7.1\%) and colorectal cancer (6.1\%). Lung cancer has the highest mortality (18.4\%), followed by colorectal cancer (9.2\%), stomach cancer (8.2\%), and liver cancer (8.2\%) [8].

*Correspondence: sckang@daegu.ac.kr

Department of Biotechnology, Daegu University, Gyeongsan, Gyeongbuk 38453, Republic of Korea
Cell death is one of the most significant processes responsible for maintaining homeostasis, by controlling the cell turnover in the body. Based on their biochemical and morphological characteristic, the cellular mortality processes, either due to an inbuilt programmed signaling mechanism or as a result of certain pathological outcomes, are classified into three major categories: (i) autophagy, (ii) apoptosis, and (iii) necrosis $[9,10]$. Autophagy is a complex process, and its dysregulation can contribute to the development and progression of cancer. Targeting autophagy can serve as an effective therapeutic strategy in cancer. In the autophagy process, molecular targets have been identified from autophagy induction to lysosomal degradation. The generation of resistance limits the efficiency of current therapeutics (radiotherapy, chemotherapy, immune checkpoint inhibitors, and molecular targeted therapy) in various cancers in response to these therapies.

This poses a need to develop novel therapeutics that can overcome the resistance in a wide variety of cancers and be more effective and safe with low toxicity. For this purpose, natural compounds have drawn the attention of 
researchers as promising prophylactic and therapeutic strategies for cancer $[11,12]$.

Celastrol (Cel; Fig. 1) is a quinone methide triterpene present in TWHF root extracts. It is widely recognized as a pharmacologically active compound used in various diseases such as autoimmune, inflammatory diseases, and cancer. The atomic orbital energy analysis reveals that because of the presence of carbon $\mathrm{C}_{2}$ on the A-ring and $\mathrm{C}_{6}$ on the B-ring of celastrol, it is highly susceptible to a nucleophilic attack (Fig. 2) [13]. The quinone methide structure in celastrol has the affinity to react with the

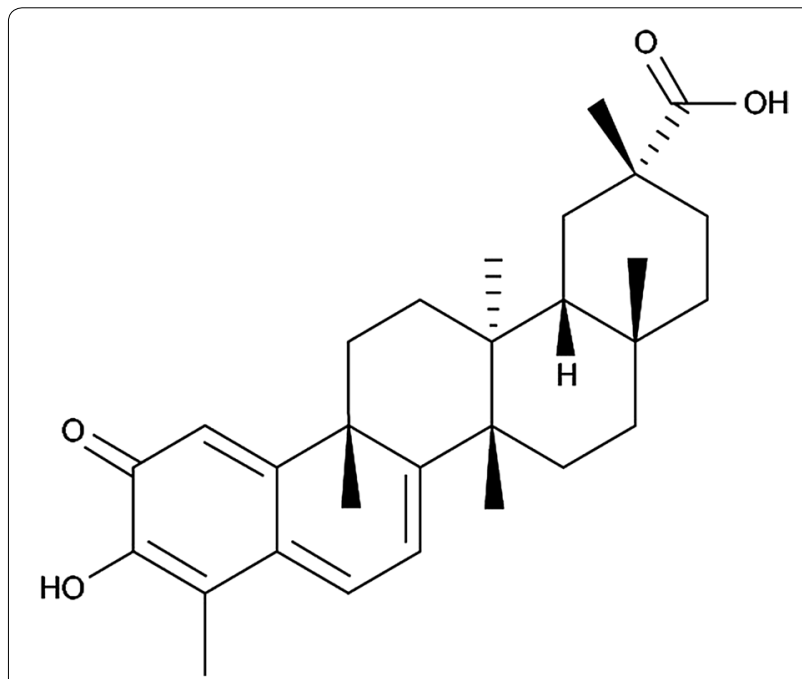

Fig. 1 Chemical structure of celastrol [adapted from Ref. [97]) thiol groups of the cysteine residues of Cdc37 to form covalent Michael adducts, resulting in the disruption of chaperons or co-chaperones (such as Cdc37-Hsp90 complex) which play a significant role in the stabilization and folding of oncogenic kinases [14]. Some other chaperons/ cochaperones proposed to be the target for celastrol in in-vitro studies are p23 [15], IKK $\beta$ [16], and the proteasome. This mechanism seems to be one of the major factors responsible for multiple targets of celastrol.

Recent studies have highlighted the potential of celastrol in the treatment of numerous different cancers. Data derived from different animal models and cell lines, attribute the anticancer properties to (i) angiogenesis inhibition, (ii) cell death activation, (iii) anti-invasive effects, and (iv) sensitizing the cells to conventional therapies. Celastrol has been reported to inhibit cancer cell progression and induction of cell death in various cancers such as breast, lung, glioblastoma, hepatoma, nasopharyngeal, prostate, myeloma, colon, pancreas, liver, leukaemia, melanoma, gastric cancer, and osteosarcoma.

\section{Pharmacological activities of natural compounds isolated from Tripterygium wilfordii}

Tripterygium wilfordii Hook $F$ (TWHF) is widely known as Thunder of God Vine and has a long history in the treatment of rheumatoid arthritis (RA) [17-19]. The root bark of the plant has shown significant pharmacological activities against autoimmune disorders [20], inflammation [21, 22], kidney diseases [23], atherosclerosis, fibrosis, and neurodegeneration [24]. Several bioactive compounds have been isolated from the plant, including

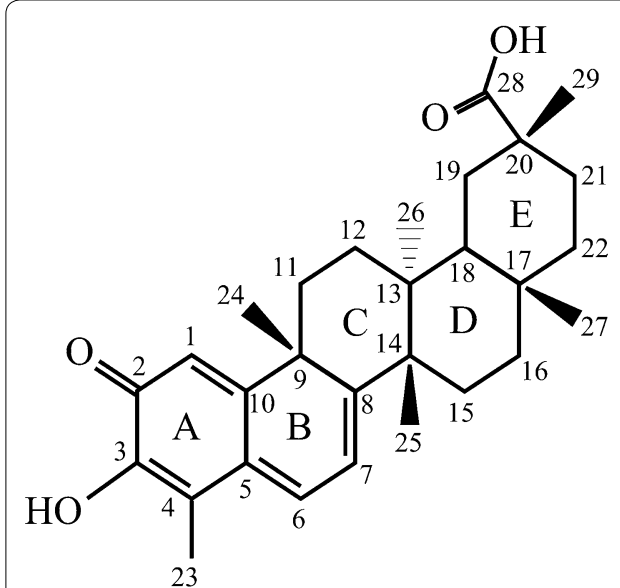

I

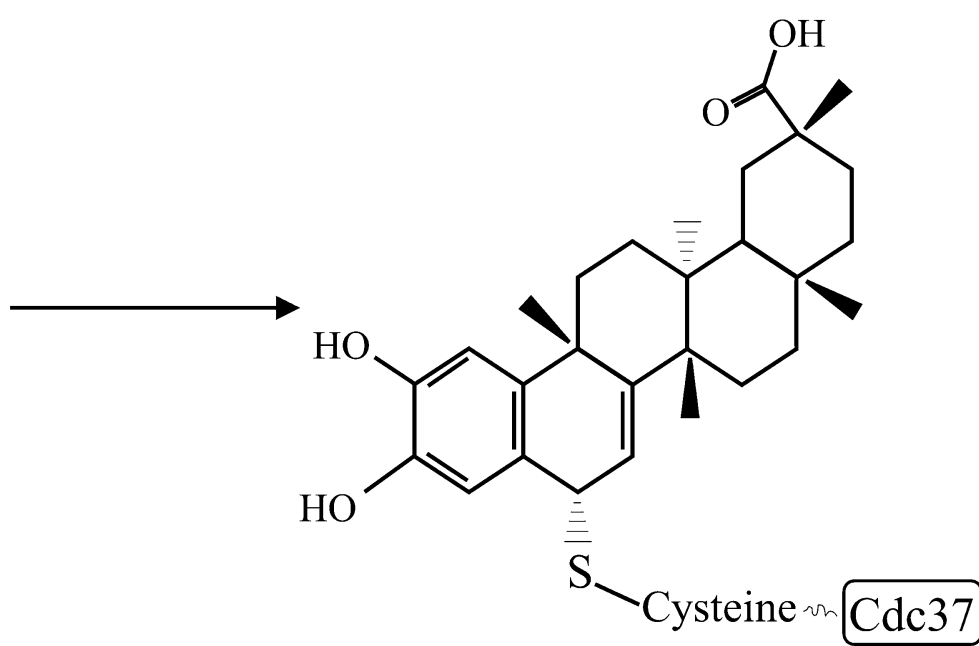

II

Fig. 2 The electrophilic sites with positions C2 (Ring A) and C6 (Ring B) in the structure of quinone methide rings (I):-, these sites are susceptible to the nucleophilic attack of thiol groups of cysteine residues to form covalent protein adducts (II) [14] 
sesquiterpenes, glycosides, lignans, alkaloids, diterpenes (triptonide, tripdiolide, and triptolide), and triterpenes (pristimerin, wilforlide A and celastrol) $[18,25,26]$. Of these, celastrol is considered the promising and most active compound of the plant.

\section{Anticancer activities of celastrol}

The anticancer potential of celastrol has been widely investigated in vivo in several disease models (Table 1). The development and growth of melanoma xenograft in the mouse models are effectively inhibited by celastrol in a dose-dependent manner [27]. The celastrol treatment has also been shown to suppress the in vitro and in vivo proliferation of bladder cancer cells and osteosarcoma, followed by the induction of autophagy $[28,29]$. The viability of HepG2 is inhibited by the disruption of certain signaling pathways when exposed to celastrol alone [30] and affects the expression of EGFR when administered in combination with lapatinib [31]. Treatment with celastrol inhibits the growth of MCF-7 breast cancer cells [32] and causes the induction of apoptosis in HT-29 colon adenocarcinoma cells [33]. The invasion and proliferation of colitis-related colon cancer and NSCLC are suppressed when exposed to celastrol in a dose-dependent manner $[34,35]$. Invasion, proliferation, and migration of chondrosarcoma cells are also in vivo [36]. Celastrol stimulates an energy crisis by ATP depletion and induces lipid accumulation, leading to cell cycle arrest and cell death in cancer cells [37]. Celastrol also induces ER stress, leading to growth inhibition of head and neck cancer cells [38].

\section{Signaling pathways associated with celastrol-mediated autophagy regulation}

The capability of celastrol to induce autophagy in a variety of cancer cells displays the potential of the compound to modulate multiple signaling pathways (Fig. 3). In various preclinical mouse models, celastrol inhibits the proliferation of tumors by affecting the expression of pro-survival transcription factors and various cellcycle molecules. Autophagy related markers were identified in cancer cells treated with celastrol and by applying autophagy inhibitors to down-regulate specific markers [39-45]. In the current review, we focus on summarizing the role of celastrol in cancer therapeutics and giving an overview of the signaling pathways associated with celastrol-mediated autophagy regulation in cancer.

\section{Celastrol induces autophagy via regulation of PI3K/AkT/ mTOR pathway}

Numerous studies have confirmed the relationship of PI3K, AkT and mTOR pathways with cancer, and their inhibition via autophagy regulation has shown significant results in cancer treatment $[46,47]$. These three pathways are linked with each other. AkT was originally identified as an important element in the intracellular signaling of the insulin receptor and is now considered as the significant downstream effector of PI3K activation [48]. PI3K activation results in AkT phosphorylation subsequent to translocation to the inner membrane [49]. The modification of AkT is enough to activate mTOR, which then promotes cell survival and increases protein synthesis by phosphorylating its effectors such as S6K1 and S6K2 [50]. Celastrol has shown a promising role in inducing autophagy by disrupting PI3K/AkT/mTOR pathways (Fig. 4). The disruption of these pathways leads to the autophagy-mediated cell death of cancer cells [27, 51, 52]. The pathways mentioned above are significant for cancer therapy and important for inducing autophagy in the intestine, which could serve as an effective target for treating Crohn's disease (CD) [53].

\section{Celastrol induces autophagy and promotes G2/M phase arrest via the ROS/JNK signaling pathway}

As reported in several studies, ROS generation in excess interferes with various signaling pathways of the cells [54-57]. Additionally, JNK of the MAPK family plays a pivotal role in regulating autophagy [58-60]. Recent studies have highlighted the role of cancer cell survival via synergistic action of JNK with JAK/STAT, NF- $\mathrm{BB}$ and other molecules. The pro-survival effect of JNK can be attributed to the immune evasion phenomena mediated by TLR, IFN- $\gamma$ and TGF- $\beta$ [61]. Celastrol results in phosphorylation of JNK and increases ROS generation, thereby further promoting autophagy in osteosarcoma cells. Application of ROS inhibitors (such as NAC) reverses the celastrol-induced autophagy and blocks the G2/M phase arrest. However, significant attenuation can be observed when JNK inhibitors are used, but with no impact on G2/M arrest. The phosphorylation of JNK is eliminated by NAC (ROS inhibitor), however, the JNK inhibitor does not affect ROS generation, thereby suggesting ROS as a proximal event for JNK [28].

$\mathrm{G} 2 / \mathrm{M}$ is one of the other frontiers serving as a suitable target for anticancer therapy [62]. The cyclin B1 complex promotes the $\mathrm{G} 2 / \mathrm{M}$ phase transitions, which remains in the inactivate form by phosphorylation, and the regulation is accomplished by a group of proteins such as Cdc2, Cdc25C, and Chk1/2 [63-65]. The expression levels of Chk2, phospho-Chk2, phospho-Cdc2, phospho-Cdc25C, cyclin B1 and p21 are upregulated with celastrol treatment, however, the level of Cdc2 and Cdc25C is downregulated. The level of cyclin $\mathrm{B} 1$ is observed to increase with suppression of the $\mathrm{Cdc} 2$ activity, which promotes the degradation of cyclin B1 via ubiquitin-dependent proteolysis [66]. The up-regulation of cyclin B1 results in the $\mathrm{G} 2 / \mathrm{M}$ phase arrest in cancer cells, thus suppressing 


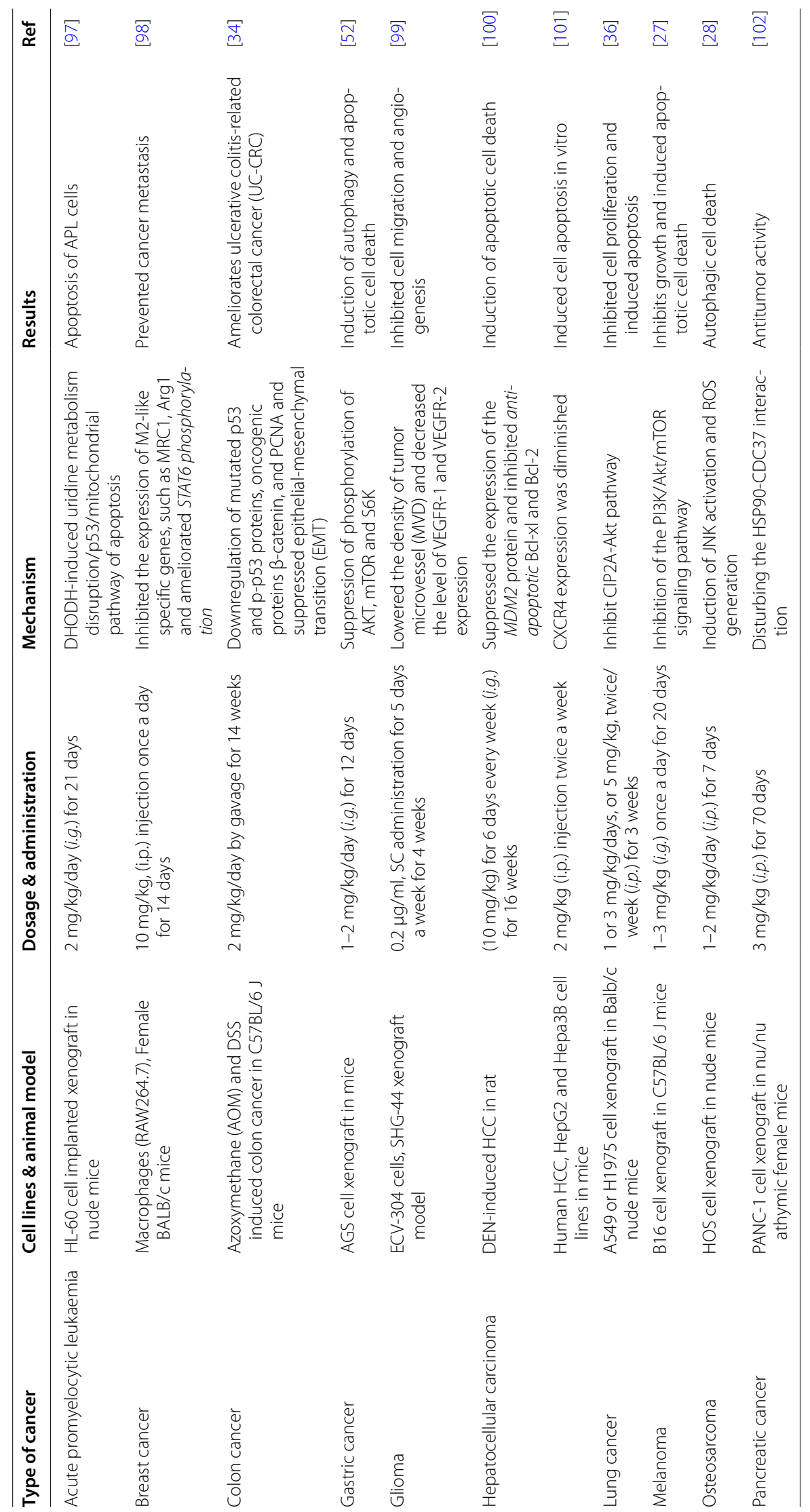




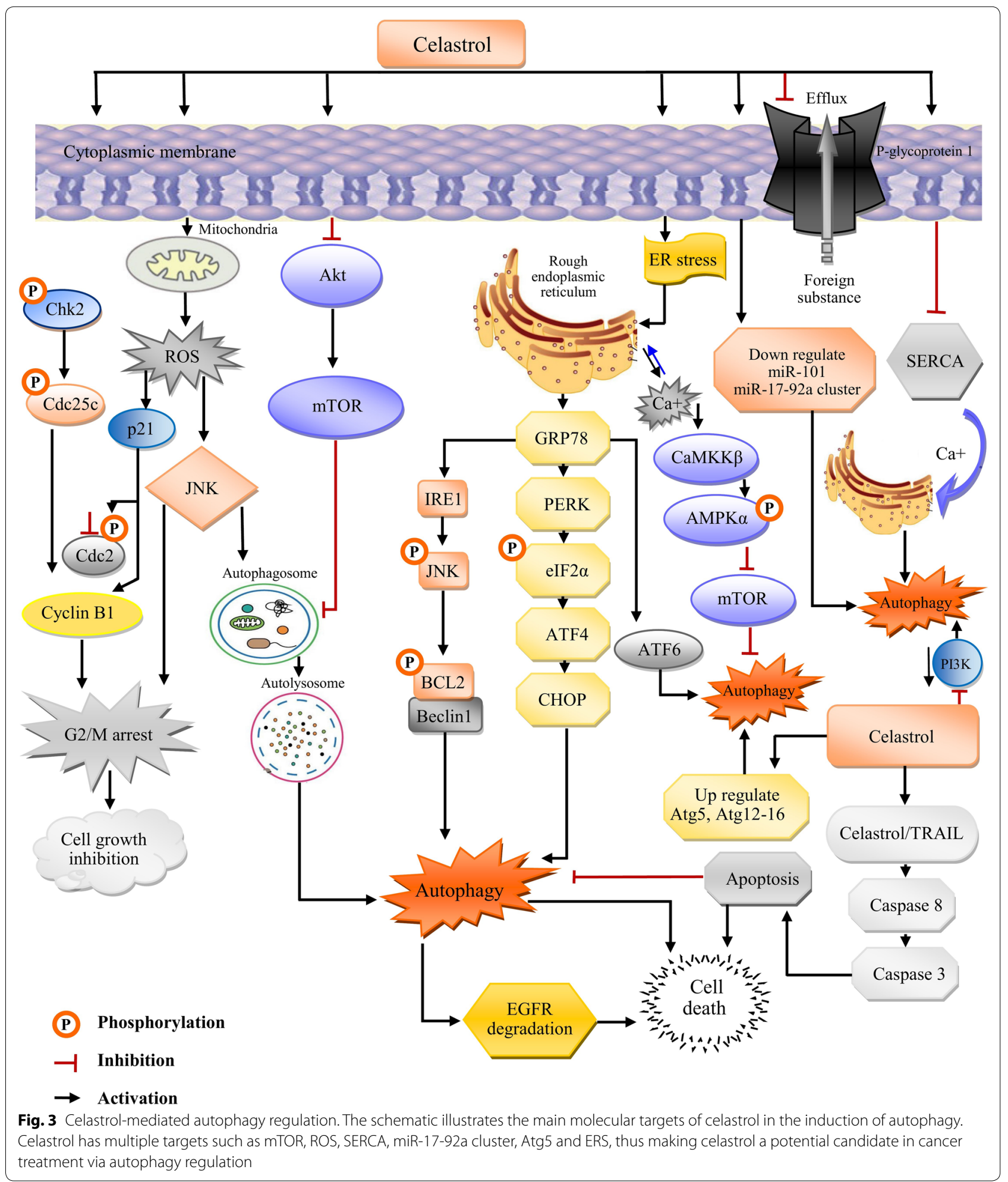

cell proliferation $[65,67]$. These findings are confirmed by a study that reported that exposure to celastrol inhibits human osteosarcoma's development and proliferation through autophagy and G2/M arrest. It was also revealed that when the apoptosis was blocked in these cells with suitable inhibitors, the cells died via autophagy; conversely, suppression of autophagy inhibited PARP's 


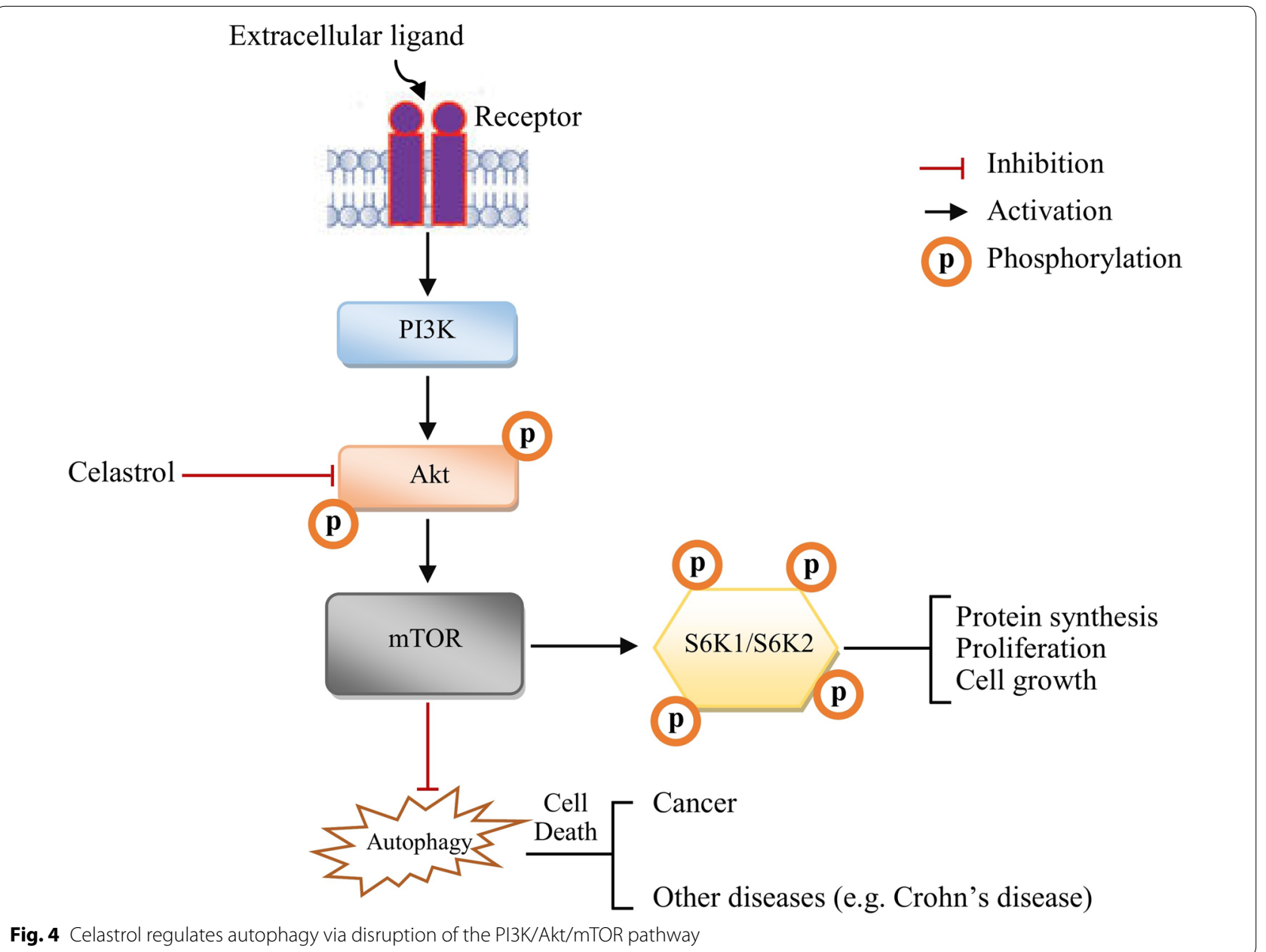

cleavage and caspase-3, thereby leading to apoptotic cell death [28].

\section{Celastrol promotes ER stress/UPR mediated apoptosis and autophagy}

In the endoplasmic reticulum (ER) lumen, inappropriately folded proteins accumulate due to internal and external factors in the tumor microenvironment. This accumulation causes ER stress, which results in the activation of Unfolded Protein Response (UPR), an adaptive mechanism for restoring protein homeostasis in the ER. The IRE1 $\alpha$ activation and splicing of XBP1 initiate UPR, and these factors are responsible for the transcription of enzymes, particularly chaperons that return to the ER and restore homeostasis. Several studies have linked UPR signaling with different aspects of tumor progression and carcinogenesis [68]. Treatment of different cancer cells (including HCC) with celastrol causes ER stress, with subsequent activation of the UPR for maintaining homeostasis [69]. The proteasome can degrade the unrequired or damaged proteins, but celastrol has an inhibitory effect on proteasome in various cancer cells such as prostate cancer and glioblastoma [70]. In non-functional or disrupted UPR, the homeostasis of protein folding cannot be restored; the persistent stress thereby causes a cascade of events that leads to apoptosis [71].

When the misfolded proteins are not restored or degraded by the proteasome, the UPR mechanism also regulates autophagy [72]. It means that by causing extracellular stress, celastrol not only leads to apoptosis and causes UPR mediated autophagy induction in cancer cells. In HCC, celastrol mediated autophagy was observed through transcription factor of ER stress, and UPR expression induced expression of autophagyrelated proteins [73]. However, the direct association between ER stress and celastrol mediated cell death in HCC is not clearly understood and needs further research for understanding the correlation, which will give new insight into the celastrol mediated anticancer effects in HCC [74]. 
Celastrol induces autophagy by targeting AR, downregulating the miR-17-92a cluster and miR-101

There are some genes and signaling pathways that result in the inhibition of autophagy. One of the important reported gene clusters is miR-17-92a, which exerts a negative role in regulating autophagy. The cluster is transactivated by the androgen receptor (AR) in cancer cells such as prostate cancer [75], and seed sequences have established it as a group of four families: miR-17, miR-18, miR-19, and miR-92 [76]. The dissection of miR-17-92a cluster determined the role of the miR-17 seed family (miR-17 and miR-20) as an autophagy inhibitor in prostate cancer. Another miR-17 family member, known as miR-106, targets the ULK1 to suppress leucine deprivation-induced autophagy in myoblast cells or mycobacteria invasion mediated autophagy [77, 78]. In another study, autophagy in the intestinal epithelial HCT116 cells was inhibited by binding miR-106 to the 30 UTR region of ATG16L [79]. In prostate cancer, several autophagyrelated genes serve as suitable targets for the miR-17 seed family, and until now, only the expression of ATG7 is shown to be disrupted when cells are transfected with miR-17 or miR-20a.

Another similar gene (known as miR-101) has also been identified. miR-101 is reported to be an autophagy inhibitor, having a dual role in suppressing both autophagy induction and maturation by targeting the STMN1, RAB5A, and ATG4D genes [80]. However, the AR binding site has been predicted at upstream of the miR-101 gene [81]. Celastrol is highly effective by targeting the AR, promoting the destabilization of AR through inhibition of HSP90, or suppressing calpain activation $[82,83]$. Blocking the AR pathway induces autophagy in AR-positive prostate cancer cells [84-87]. Destabilization of the AR results in suppressing the miR-17-92a cluster and miR-101, subsequently leading to the induction of autophagy in cancer cells [75]. However, the mechanism by which AR regulates autophagy is not fully understood.

\section{Celastrol inhibits SERCA leading to autophagy induction in MDR cancer cells}

Some transporter proteins play a significant role in autophagy regulation. The most important and extensively studied transporter is the calcium transporter known as sarcoplasmic/endoplasmic reticulum (SR/ ER) $\mathrm{Ca}^{2+}$-ATPase (SERCA) located in the membranes of ER/SR [88]. Few studies have revealed that autophagy and apoptosis are effectively triggered by SERCA inhibition in cancer cells; hence, SERCA is considered a novel therapeutic target for anticancer drugs $[89,90]$. SERCA has a prominent role in tumor survival [91], and its inhibition causes a severe imbalance in calcium homeostasis in tumor cells, leading to activation of the ER stress response. This results in permanent damage to mitochondria by $\mathrm{Ca}^{2+}$ excess and affects the caspase and cytochrome- $\mathrm{C}$ release pathway [92].

Celastrol is reported to effectively mobilize the cytosolic calcium by directly suppressing ATP depletion and SERCA, thereby leading to autophagic and apoptotic cell death in MDR cancer cells. Autophagy is induced via the CaMKK $\beta$-AMPK-mTOR signaling pathway. Additionally, celastrol effectively inhibits the ABC-transporter P-gp, which increases the sensitivity of MDR cancer cells and promotes the sensitization of cancer cells to taxol exposure [93]. These findings are in agreement with the findings of another study conducted by Liu et al., which reported that PERK phosphorylation and SERCA2B suppression are successfully modulated by celastrol, leading to autophagic cell death of cancer cells [94].

\section{Celastrol induced EGFR degradation via autophagy regulation}

Drug resistance is one of the alarming consequences of current anti-cancer therapies. In non-small cell lung cancer (NSCLC), the resistance is associated with a mutation in the epidermal growth factor receptor (EGFR). Celastrol shows selective cytotoxic activity against the EGFR mutant NSCLCs. Moreover, via the mechanism of calcium-mediated autophagy, celastrol significantly degrades EGFR and Akt expression in both mutant and wild type NSCLCs. Application of the autophagic inhibitor or calcium chelator blocks the degradation of EGFR and decreases cell death in H1975 gefitinib-resistant NSCLCs [95].

The relationship between autophagy, EGFR, and cancer has further been illustrated by So et al. [96]. This was verified by exposing NSCLCs to CK2 inhibitor; autophagy was induced, which subsequently downregulated the EGFR, leading to cell death. The autophagy triggered by CK2 inhibitors might differ from the autophagic pathways activated by celastrol, but it provides evidence that celastrol is a potential agent for the induction of autophagic-mediated EGFR degradation and can be an effective anticancer therapy for such resistant cancer cells [95].

\footnotetext{
Abbreviations

AMPK: AMP-activated protein kinase; ATP: Adenosine triphosphate; BNIP3: BCL2/adenovirus E1B 19 kDa protein-interacting protein 3; CDC: Cell division cycle; CDK: Cyclin dependent kinase; Chk: Checkpoint kinase; DHODH: Dihydroorotate dehydrogenase; EGFR: Epidermal growth factor receptor; elF2a: Eukaryotic translation initiation factor 2a; EMT: Epithelial-mesenchymal transition; ER: Endoplasmic reticulum; GalN: Galactosamine; HCC: Hepatocellular carcinoma; HIF1A: Hypoxia-inducible factor 1-alpha; HSF: Heat shock factor; HSP: Heat shock protein; ICAM1: Intercellular Adhesion Molecule 1; IL: Interleukin; LPS: Lipopolysaccharide; JNK: C-Jun N-terminal kinases; MAPK: Mitogen-activated protein kinase; MDR: Multi-drug resistance; MLKL: Mixed lineage kinase domain like pseudo-kinase; miR cluster: MicroRNA clusters;
} 
mTOR: Mammalian target of rapamycin; MRC1: Mannose receptor C-type 1; MVD: Micro vessel density; NF-rB: Nuclear factor kappa-light-chain-enhancer of activated B cells; NLRP3: NLR family pyrin domain containing 3; NSCLC: Non-small cell lung carcinoma; PCNA: Proliferating cell nuclear antigen; PGC1a: Peroxisome proliferator-activated receptor gamma coactivator 1a; RA: Rheumatoid arthritis; RIP3: Receptor-interacting serine/threonine-protein; PERK: Protein kinase R (PKR)-like endoplasmic reticulum kinase; PI3K: Phosphoinositide 3-kinases; ROS: Reactive oxygen species; SERCA: Sarcoplasmic/ endoplasmic reticulum $\mathrm{Ca}^{2+}$-ATPase; TRAF2: TNF receptor-associated factor 2; TRAIL: TNF-related apoptosis-inducing ligand; TNF: Tumor necrosis factor; UPR: Unfolded protein response; VEGFR: Vascular endothelial growth factor receptor; XBP1: $\mathrm{X}$ box binding protein 1 .

\section{Acknowledgements}

Not applicable.

\section{Authors' contributions}

SCK designed the work. MH wrote the manuscript. SCK revised the manuscript. Both authors read and approved the final manuscript.

\section{Funding}

Not applicable.

\section{Availability of data and materials}

The data sets presented in this study are included in the article.

\section{Ethics approval}

Not applicable.

\section{Consent for publication}

Not applicable.

\section{Competing interests}

The authors declare that there is no competing interests.

Received: 15 September 2020 Accepted: 7 November 2020

Published online: 25 November 2020

\section{References}

1. Aruoma Ol, Bahorun T, Agnihotri AK (2014) Cancer risks and perspectives: molecular mechanisms. Mut Res Fundam Mol Mech Mutagen 768:1-5

2. Bagnardi V, Rota M, Botteri E, Tramacere I, Islami F, Fedirko V, Scotti L, Jenab M, Turati F, Pasquali E (2015) Alcohol consumption and sitespecific cancer risk: a comprehensive dose-response meta-analysis. Br J Cancer 112(3):580-593

3. Gallagher EJ, Novosyadlyy R, Yakar S, LeRoith D (2010) The increased risk of cancer in obesity and type 2 diabetes: potential mechanisms. Principles of Diabetes Mellitus. Springer, Berlin, pp 579-599

4. Leon ME, Peruga A, McNeill A, Kralikova E, Guha N, Minozzi S, Espina C, Schuez J (2015) European code against cancer: tobacco and cancer. Cancer Epidemiol 39:S20-S33

5. Massarweh NN, El-Serag HB (2017) Epidemiology of hepatocellular carcinoma and intrahepatic cholangiocarcinoma. Cancer Control 24(3):1073274817729245

6. Raaschou-Nielsen O, Beelen R, Wang M, Hoek G, Andersen ZJ, Hoffmann B, Stafoggia M, Samoli E, Weinmayr G, Dimakopoulou K (2016) Particulate matter air pollution components and risk for lung cancer. Environ Int 87:66-73

7. Taylor C, Correa C, Duane FK, Aznar MC, Anderson SJ, Bergh J, Dodwell D, Ewertz M, Gray R, Jagsi R (2017) Estimating the risks of breast cancer radiotherapy: evidence from modern radiation doses to the lungs and heart and from previous randomized trials. J Clin Oncol 35(15):1641

8. Bray F, Ferlay J, Soerjomataram I, Siegel RL, Torre LA, Jemal A (2018) Global cancer statistics 2018: GLOBOCAN estimates of incidence and mortality worldwide for 36 cancers in 185 countries. CA Cancer J Clin 68(6):394-424

9. Galluzzi L, Vitale I, Aaronson SA, Abrams JM, Adam D, Agostinis P, Alnemri ES, Altucci L, Amelio I, Andrews DW (2018) Molecular mechanisms of cell death: recommendations of the Nomenclature Committee on Cell Death 2018. Cell Death Differ 25(3):486-541

10. Mohammadinejad R, Ahmadi Z, Tavakol S, Ashrafizadeh M (2019) Berberine as a potential autophagy modulator. J Cell Physiol 234(9):14914-14926

11. Tian Y, Song W, Li D, Cai L, Zhao Y (2019) Resveratrol as a natural regulator of autophagy for prevention and treatment of cancer. OncoTargets Ther 12:8601

12. Dinku W, Isaksson J, Rylandsholm FG, Bouř P, Brichtová E, Choi SU, Lee S-H, Jung Y-S, No ZS, Svendsen JSM (2020) Anti-proliferative activity of a novel tricyclic triterpenoid acid from Commiphora africana resin against four human cancer cell lines. Appl Biol Chem 63(1):1-11

13. Salminen A, Lehtonen M, Paimela T, Kaarniranta K (2010) Celastrol: Molecular targets of Thunder God Vine. Biochem Biophys Res Commun 394(3):439-442

14. Sreeramulu S, Gande SL, Göbel M, Schwalbe H (2009) Molecular mechanism of inhibition of the human protein complex Hsp90-Cdc37, a kinome chaperone-cochaperone, by triterpene celastrol. Angew Chem Int Ed 48(32):5853-5855

15. Chadli A, Felts SJ, Wang Q, Sullivan WP, Botuyan MV, Fauq A, RamirezAlvarado M, Mer G (2010) Celastrol inhibits Hsp90 chaperoning of steroid receptors by inducing fibrillization of the Co-chaperone p23. J Biol Chem 285(6):4224-4231

16. Lee J-H, Koo TH, Yoon H, Jung HS, Jin HZ, Lee K, Hong Y-S, Lee JJ (2006) Inhibition of NF-KB activation through targeting IKB kinase by celastrol, a quinone methide triterpenoid. Biochem Pharmacol 72(10):1311-1321

17. Peterson RT, Schreiber SL (1998) Translation control: connecting mitogens and the ribosome. Curr Biol 8(7):R248-R250

18. Bao J, Dai S-M (2011) A Chinese herb Tripterygium wilfordii Hook F in the treatment of rheumatoid arthritis: mechanism, efficacy, and safety. Rheumatol Int 31(9):1123-1129

19. Law SK-Y, Simmons MP, Techen N, Khan IA, He M-F, Shaw P-C, But PP-H (2011) Molecular analyses of the Chinese herb Leigongteng (Tripterygium wilfordii Hook.f.). Phytochemistry 72(1):21-26

20. Chen Y-Z, Gao Q, Zhao X-Z, Chen X-M, Zhang F, Chen J, Xu C-G, Sun L-L, Mei C-L (2010) Meta-analysis of Tripterygium wilfordii Hook F in the immunosuppressive treatment of IgA nephropathy. Intern Med 49(19):2049-2055

21. Liu Y, Chen H-L, Yang G (2010) Extract of Tripterygium wilfordii Hook $F$ protect dopaminergic neurons against lipopolysaccharide-induced inflammatory damage. Am J Chin Med 38(04):801-814

22. Xue M, Jiang Z-Z, Wu T, Li J, Zhang L, Zhao Y, Li X-j, Zhang L-Y, Yang S-y (2012) Anti-inflammatory effects and hepatotoxicity of Tripterygiumloaded solid lipid nanoparticles on adjuvant-induced arthritis in rats. Phytomedicine 19(11):998-1006

23. Wan Y-G, Che X-Y, Sun W, Huang Y-R, Meng X-J, Chen H-L, Shi X-M, Tu Y, Wu W, Liu Y-L (2014) Low-dose of multi-glycoside of Tripterygium wilfordii Hook. f., a natural regulator of TGF- $\beta 1 /$ Smad signaling activity improves adriamycin-induced glomerulosclerosis in vivo. J Ethnopharmacol 151(3):1079-1089

24. Choi B-S, Sapkota K, Kim S, Lee HJ, Choi H-S, Kim S-J (2010) Antioxidant activity and protective effects of Tripterygium regelii extract on hydrogen peroxide-induced injury in human dopaminergic cells, SH-SY5Y. Neurochem Res 35(8):1269-1280

25. Li C-J, Xie F-G, Yang J-Z, Luo Y-M, Chen X-G, Zhang D-M (2012) Two sesquiterpene pyridine alkaloids and a triterpenoid saponin from the root barks of Tripterygium hypoglaucum. J Asian Nat Prod Res 14(10):973-980

26. Wang C, Li C-J, Yang J-Z, Ma J, Chen X-G, Hou Q, Zhang D-M (2013) Antiinflammatory sesquiterpene derivatives from the leaves of Tripterygium wilfordii. J Nat Prod 76(1):85-90

27. Lee J-H, Won Y-S, Park K-H, Lee M-K, Tachibana H, Yamada K, Seo K-I (2012) Celastrol inhibits growth and induces apoptotic cell death in melanoma cells via the activation ROS-dependent mitochondrial pathway and the suppression of PI3K/AKT signaling. Apoptosis 17(12):1275-1286

28. Li HY, Zhang J, Sun LL, Li BH, Gao HL, Xie T, Zhang N, Ye ZM (2015) Celastrol induces apoptosis and autophagy via the ROS/JNK signaling pathway in human osteosarcoma cells: an in vitro and in vivo study. Cell Death Dis 6(1):e1604-e 
29. Yu X, Zhou X, Fu C, Wang Q, Nie T, Zou F, Guo R, Liu H, Zhang B, Dai M (2015) Celastrol induces apoptosis of human osteosarcoma cells via the mitochondrial apoptotic pathway. Oncol Rep 34(3):1129-1136

30. Shen Y-f, Zhang X, Wang Y, Cao F-f, Uzan G, Peng B, Zhang D-h (2016) Celastrol targets IRAKs to block Toll-like receptor 4-mediated nuclear factor-KB activation. J Integr Med 14(3):203-208

31. Yan Y, Guo Y, Zhang W, Ma C, Zhang Y, Wang C, Wang H (2014) Celastrol enhanced the anticancer effect of lapatinib in human hepatocellular carcinoma cells in vitro. J BUON 19(2):412-418

32. Kim JH, Lee JO, Lee SK, Kim N, You GY, Moon JW, Sha J, Kim SJ, Park SH, Kim HS (2013) Celastrol suppresses breast cancer MCF-7 cell viability via the AMP-activated protein kinase (AMPK)-induced p53-polo like kinase 2 (PLK-2) pathway. Cell Signal 25(4):805-813

33. Lu W, Jia G, Meng X, Zhao C, Zhang L, Ren Y, Pan H, Ni Y (2012) Betacatenin mediates the apoptosis induction effect of celastrol in HT29 cells. Life Sci 91(7-8):279-283

34. Lin L, Sun Y, Wang D, Zheng S, Zhang J, Zheng C (2016) Celastrol ameliorates ulcerative colitis-related colorectal cancer in mice via suppressing inflammatory responses and epithelial-mesenchymal transition. Front Pharmacol 6:320

35. Lo lacono M, Monica V, Vavalà T, Gisabella M, Saviozzi S, Bracco E, Novello S, Papotti M, Scagliotti GV (2015) ATF2 contributes to cisplatin resistance in non-small cell lung cancer and celastrol induces cisplatin resensitization through inhibition of JNK/ATF2 pathway. Int J Cancer 136(11):2598-2609

36. Liu Z, Ma L, Wen Z-S, Hu Z, Wu F-Q, Li W, Liu J, Zhou G-B (2014) Cancerous inhibitor of PP2A is targeted by natural compound celastrol for degradation in non-small-cell lung cancer. Carcinogenesis 35(4):905-914

37. Wang H, Teriete P, Hu A, Raveendra-Panickar D, Pendelton K, Lazo JS, Eiseman J, Holien T, Misund K, Oliynyk G (2015) Direct inhibition of c-Myc-Max heterodimers by celastrol and celastrol-inspired triterpenoids. Oncotarget 6(32):32380

38. Fribley AM, Miller JR, Brownell AL, Garshott DM, Zeng Q, Reist TE, Narula N, Cai P, Xi Y, Callaghan MU, Kodali V, Kaufman RJ (2015) Celastrol induces unfolded protein response-dependent cell death in head and neck cancer. Exp Cell Res 330(2):412-422

39. Kannaiyan R, Shanmugam MK, Sethi G (2011) Molecular targets of celastrol derived from Thunder of God Vine: potential role in the treatment of inflammatory disorders and cancer. Cancer Lett 303(1):9-20

40. Kannaiyan R, Hay HS, Rajendran P, Li F, Shanmugam MK, Vali S, Abbasi T, Kapoor S, Sharma A, Kumar AP (2011) Celastrol inhibits proliferation and induces chemosensitization through down-regulation of NF-KB and STAT3 regulated gene products in multiple myeloma cells. $\mathrm{Br} J$ Pharmacol 164(5):1506-1521

41. Kannaiyan R, Manu KA, Chen L, Li F, Rajendran P, Subramaniam A, Lam P, Kumar AP, Sethi G (2011) Celastrol inhibits tumor cell proliferation and promotes apoptosis through the activation of c-Jun $\mathrm{N}$-terminal kinase and suppression of PI3 K/Akt signaling pathways. Apoptosis 16(10):1028

42. Shanmugam MK, Ahn KS, Lee JH, Kannaiyan R, Mustafa N, Manu KA, Siveen KS, Sethi G, Chng WJ, Kumar AP (2018) Celastrol attenuates the invasion and migration and augments the anticancer effects of bortezomib in a xenograft mouse model of multiple myeloma. Front Pharmacol 9:365

43. Rajendran P, Li F, Shanmugam MK, Kannaiyan R, Goh JN, Wong KF, Wang W, Khin E, Tergaonkar V, Kumar AP (2012) Celastrol suppresses growth and induces apoptosis of human hepatocellular carcinoma through the modulation of STAT3/JAK2 signaling cascade in vitro and in vivo. Cancer Prevent Res 5(4):631-643

44. Shanmugam MK, Warrier S, Kumar AP, Sethi G, Arfuso F (2017) Potential role of natural compounds as anti-angiogenic agents in cancer. Curr Vasc Pharmacol 15(6):503-519

45. Sethi G, Ahn KS, Pandey MK, Aggarwal BB (2007) Celastrol, a novel triterpene, potentiates TNF-induced apoptosis and suppresses invasion of tumor cells by inhibiting NF-KB-regulated gene products and TAK1mediated NF-KB activation. Blood 109(7):2727-2735

46. Yan W, Ma X, Zhao X, Zhang S (2018) Baicalein induces apoptosis and autophagy of breast cancer cells via inhibiting PI3K/AKT pathway in vivo and vitro. Drug Design Dev Ther 12:3961

47. Lee HJ, Venkatarame Gowda Saralamma V, Kim SM, Ha SE, Raha S, Lee WS, Kim EH, Lee SJ, Heo JD, Kim GS (2018) Pectolinarigenin induced cell cycle arrest, autophagy, and apoptosis in gastric cancer cell via PI3K AKT/mTOR signaling pathway. Nutrients 10(8):1043

48. Boudewijn MT, Coffer PJ (1995) Protein kinase B (c-Akt) in phosphatidylinositol-3-OH kinase signal transduction. Nature 376(6541):599-602

49. Wick MJ, Dong LQ, Riojas RA, Ramos FJ, Liu F (2000) Mechanism of phosphorylation of protein kinase B/Akt by a constitutively active 3-phosphoinositide-dependent protein kinase-1. J Biol Chem 275(51):40400-40406

50. Navé BT, Ouwens DM, Withers DJ, Alessi DR, Shepherd PR (1999) Mammalian target of rapamycin is a direct target for protein kinase B: identification of a convergence point for opposing effects of insulin and amino-acid deficiency on protein translation. Biochem J 344(2):427-431

51. Deng Y-N, Shi J, Liu J, Qu Q-M (2013) Celastrol protects human neuroblastoma SH-SY5Y cells from rotenone-induced injury through induction of autophagy. Neurochem Int 63(1):1-9

52. Lee H-W, Jang KSB, Choi HJ, Jo A, Cheong J-H, Chun K-H (2014) Celastrol inhibits gastric cancer growth by induction of apoptosis and autophagy. BMB Rep 47(12):697

53. Sokollik C, Ang M, Jones NL (2011) Autophagy: a primer for the gastroenterologist/hepatologist. Can J Gastroenterol 25:667

54. Trachootham D, Alexandre J, Huang P (2009) Targeting cancer cells by ROS-mediated mechanisms: a radical therapeutic approach? Nat Rev Drug Discov 8(7):579-591

55. Chen Y, McMillan-Ward E, Kong J, Israels SJ, Gibson SB (2007) Mitochondrial electron-transport-chain inhibitors of complexes I and II induce autophagic cell death mediated by reactive oxygen species. J Cell Sci 120(23):4155-4166

56. Simon H-U, Haj-Yehia A, Levi-Schaffer F (2000) Role of reactive oxygen species (ROS) in apoptosis induction. Apoptosis 5(5):415-418

57. Jeon H-J, Kim K, Kim Y-D, Lee S-E (2019) Naturally occurring Piper plant amides potential in agricultural and pharmaceutical industries: perspectives of piperine and piperlongumine. Appl Biol Chem 62(1):1-7

58. Kyriakis JM, Banerjee P, Nikolakaki E, Dai T, Rubie EA, Ahmad MF, Avruch J, Woodgett JR (1994) The stress-activated protein kinase subfamily of c-Jun kinases. Nature 369(6476):156-160

59. Tsujimoto Y, Shimizu S (2005) Another way to die: autophagic programmed cell death. Cell Death Differ 12(2):1528-1534

60. Goss VL, Cross JV, Ma K, Qian Y, Mola PW, Templeton DJ (2003) SAPKJJNK regulates cdc2/cyclin B kinase through phosphorylation and inhibition of cdc25c. Cell Signal 15(7):709-718

61. Wu Q, Wu W, Fu B, Shi L, Wang X, Kuca K (2019) JNK signaling in cancer cell survival. Med Res Rev 39(6):2082-2104

62. Badr DA, Amer ME, Abd-Elhay WM, Nasr MS, Abuamara TM, Ali H, Mohamed AF, Youssef MA, Awwad NS, Ju Y-H (2019) Histopathological and genetic changes proved the anti-cancer potential of free and nano-capsulated sinapic acid. Appl Biol Chem 62(1):1-10

63. Peng C-Y, Graves PR, Thoma RS, Wu Z, Shaw AS, Piwnica-Worms H (1997) Mitotic and G2 checkpoint control: regulation of 14-3-3 protein binding by phosphorylation of Cdc25C on serine-216. Science 277(5331):1501-1505

64. Singh SV, Herman-Antosiewicz A, Singh AV, Lew KL, Srivastava SK, Kamath R, Brown KD, Zhang L, Baskaran R (2004) Sulforaphaneinduced G2/M phase cell cycle arrest involves checkpoint kinase 2-mediated phosphorylation of cell division cycle 25C. J Biol Chem 279(24):25813-25822

65. Zhang R, Wang Y, Li J, Jin H, Song S, Huang C (2014) The Chinese herb isolate YHL-14 induces G2/M arrest in human cancer cells by up-regulating p21 expression through P53-independent cascade. J Biol Chem M113:513960

66. Lin H, Liu XY, Subramanian B, Nakeff A, Valeriote F, Chen BD (2002) Mitotic arrest induced by XK469, a novel antitumor agent, is correlated with the inhibition of cyclin B1 ubiquitination. Int J Cancer 97(1):121-128

67. Lakin ND, Jackson SP (1999) Regulation of p53 in response to DNA damage. Oncogene 18(53):7644-7655

68. Papaioannou A, Chevet E (2017) Driving cancer tumorigenesis and metastasis through UPR signalling. Coordinating organismal physiology through the unfolded protein response. Springer, Berlin, pp 159-192

69. Ron D, Walter $P$ (2007) Signal integration in the endoplasmic reticulum unfolded protein response. Nat Rev Mol Cell Biol 8(7):519-529 
70. Dai Y, DeSano J, Tang W, Meng X, Meng Y, Burstein E, Lawrence TS, Xu $L$ (2010) Natural proteasome inhibitor celastrol suppresses androgenindependent prostate cancer progression by modulating apoptotic proteins and NF-kappaB. PLoS ONE 5(12):e14153

71. Schleicher SM, Moretti L, Varki V, Lu B (2010) Progress in the unraveling of the endoplasmic reticulum stress/autophagy pathway and cancer: implications for future therapeutic approaches. Drug Resist Updates 13(3):79-86

72. Kouroku Y, Fujita E, Tanida I, Ueno T, Isoai A, Kumagai H, Ogawa S, Kaufman R, Kominami E, Momoi T (2007) ER stress (PERK/elF2 a phosphorylation) mediates the polyglutamine-induced LC3 conversion, an essential step for autophagy formation. Cell Death Differ 14(2):230-239

73. Periyasamy P, Guo M-L, Buch S (2016) Cocaine induces astrocytosis through ER stress-mediated activation of autophagy. Autophagy 12(8):1310-1329

74. Ren B, Liu H, Gao H, Liu S, Zhang Z, Fribley AM, Callaghan MU, Xu Z, Zeng Q, Li Y (2017) Celastrol induces apoptosis in hepatocellular carcinoma cells via targeting ER-stress/UPR. Oncotarget 8(54):93039

75. Guo J, Mei Y, Li K, Huang X, Yang H (2016) Downregulation of miR-1792a cluster promotes autophagy induction in response to celastrol treatment in prostate cancer cells. Biochem Biophys Res Commun 478(2):804-810

76. Han Y-C, Vidigal JA, Mu P, Yao E, Singh I, González AJ, Concepcion CP, Bonetti C, Ogrodowski P, Carver B (2015) An allelic series of miR-17〜 92-mutant mice uncovers functional specialization and cooperation among members of a microRNA polycistron. Nat Genet 47(7):766-775

77. Duan X, Zhang T, Ding S, Wei J, Su C, Liu H, Xu G (2015) microRNA17-5p modulates bacille calmette-guerin growth in RAW264. 7 cells by targeting ULK1. PLoS ONE 10(9):e0138011

78. Wu H, Wang F, Hu S, Yin C, Li X, Zhao S, Wang J, Yan X (2012) MiR-20a and miR-106b negatively regulate autophagy induced by leucine deprivation via suppression of ULK1 expression in C2C12 myoblasts. Cell Signal 24(11):2179-2186

79. Zhai Z, Wu F, Chuang AY, Kwon JH (2013) miR-106b fine tunes ATG16L1 expression and autophagic activity in intestinal epithelial HCT116 cells. Inflamm Bowel Dis 19(11):2295-2301

80. Frankel LB, Wen J, Lees M, Høyer-Hansen M, Farkas T, Krogh A, Jäättelä $M$, Lund $A H$ (2011) microRNA-101 is a potent inhibitor of autophagy. EMBO J 30(22):4628-4641

81. Cao P, Deng Z, Wan M, Huang W, Cramer SD, Xu J, Lei M, Sui G (2010) MicroRNA-101 negatively regulates Ezh2 and its expression is modulated by androgen receptor and HIF-1a/HIF-1ß. Mol Cancer 9(1):108

82. Hieronymus H, Lamb J, Ross KN, Peng XP, Clement C, Rodina A, Nieto M, Du J, Stegmaier K, Raj SM (2006) Gene expression signature-based chemical genomic prediction identifies a novel class of HSP90 pathway modulators. Cancer Cell 10(4):321-330

83. Yang H, Murthy S, Sarkar FH, Sheng S, Reddy GPV, Dou QP (2008) Calpain-mediated androgen receptor breakdown in apoptotic prostate cancer cells. J Cell Physiol 217(3):569-576

84. Bennett H, Fleming J, O'prey J, Ryan K, Leung H (2010) Androgens modulate autophagy and cell death via regulation of the endoplasmic reticulum chaperone glucose-regulated protein 78/BiP in prostate cancer cells. Cell Death Dis 1(9):e72-e

85. Chhipa RR, Wu Y, Ip C (2011) AMPK-mediated autophagy is a survival mechanism in androgen-dependent prostate cancer cells subjected to androgen deprivation and hypoxia. Cell Signal 23(9):1466-1472

86. Jiang Q, Yeh S, Wang X, Xu D, Zhang Q, Wen X, Xia S, Chang C (2012) Targeting androgen receptor leads to suppression of prostate cancer via induction of autophagy. J Urol 188(4):1361-1368
87. Li M, Jiang X, Liu D, Na Y, Gao GF, Xi Z (2008) Autophagy protects LNCaP cells under androgen deprivation conditions. Autophagy 4(1):54-60

88. Ebashi F, Ebashi S (1962) Removal of calcium and relaxation in actomyosin systems. Nature 194(4826):378-379

89. Denmeade SR, Isaacs JT (2005) The SERCA pump as a therapeutic target: making a "smart bomb" for prostate cancer. Cancer Biol Ther 4(1):21-29

90. Yorimitsu T, Nair U, Yang Z, Klionsky DJ (2006) Endoplasmic reticulum stress triggers autophagy. J Biol Chem 281(40):30299-30304

91. Denmeade SR, Jakobsen CM, Janssen S, Khan SR, Garrett ES, Lilja H, Christensen SB, Isaacs JT (2003) Prostate-specific antigen-activated thapsigargin prodrug as targeted therapy for prostate cancer. J Natl Cancer Inst 95(13):990-1000

92. Schönthal AH (2009) Endoplasmic reticulum stress and autophagy as targets for cancer therapy. Cancer Lett 275(2):163-169

93. Xu S-W, Law BYK, Qu SLQ, Hamdoun S, Chen J, Zhang W, Guo J-R, Wu A-G, Mok SWF, Zhang DW (2020) SERCA and P-glycoprotein inhibition and ATP depletion are necessary for celastrol-induced autophagic cell death and collateral sensitivity in multidrug-resistant tumor cells. Pharmacol Res 153:104660

94. Liu J, Lee J, Hernandez MAS, Mazitschek R, Ozcan U (2015) Treatment of obesity with celastrol. Cell 161(5):999-1011

95. Xu S-W, Law BYK, Mok SWF, Leung ELH, Fan XX, Coghi PS, Zeng W, Leung C-H, Ma D-L, Liu L (2016) Autophagic degradation of epidermal growth factor receptor in gefitinib-resistant lung cancer by celastrol. Int J Oncol 49(4):1576-1588

96. So KS, Kim CH, Rho JK, Kim SY, Choi YJ, Song JS, Kim WS, Choi CM, Chun YJ, Lee JC (2014) Autophagosome-mediated EGFR down-regulation induced by the CK2 inhibitor enhances the efficacy of EGFR-TKI on EGFR-mutant lung cancer cells with resistance by T790M. PLOS ONE 9(12):e114000

97. Zhang X, Yang J, Chen M, Li L, Huan F, Li A, Liu Y, Xia Y, Duan J-a, Ma S (2016) Metabolomics profiles delineate uridine deficiency contributes to mitochondria-mediated apoptosis induced by celastrol in human acute promyelocytic leukemia cells. Oncotarget 7(29):46557

98. Yang Y, Cheng S, Liang G, Honggang L, Wu H (2018) Celastrol inhibits cancer metastasis by suppressing M2-like polarization of macrophages. Biochem Biophys Res Commun 503(2):414-419

99. Zhou Y-x, Huang Y-I (2009) Antiangiogenic effect of celastrol on the growth of human glioma: anin vitroandin vivostudy. Chin Med J 122(14):1666-1673

100. Chang W, He W, Li P-P, Song S-S, Yuan P-F, Lu J-T, Wei W (2016) Protective effects of Celastrol on diethylnitrosamine-induced hepatocellular carcinoma in rats and its mechanisms. Eur J Pharmacol 784:173-180

101. Kun-Ming C, Chih-Hsien C, Chen-Fang L, Ting-Jung W, Hong-Shiue C, Wei-Chen $L$ (2020) Potential anticancer effect of celastrol on hepatocellular carcinoma by suppressing CXCR4-related signal and impeding tumor growth in vivo. Arch Med Res 51:297

102. Zhang T, Hamza A, Cao X, Wang B, Yu S, Zhan C-G, Sun D (2008) A novel Hsp90 inhibitor to disrupt Hsp90/Cdc37 complex against pancreatic cancer cells. Mol Cancer Ther 7(1):162-170

\section{Publisher's Note}

Springer Nature remains neutral with regard to jurisdictional claims in published maps and institutional affiliations. 